\title{
Distribution of Metastatic Cancer Cells in Colorectal Mesentery
}

\author{
Chen-Sen $\mathrm{Ma}^{1}{ }^{1}$ (D) $\cdot$ Yi-Xin Tong ${ }^{1} \cdot$ Jian-Ping Gong ${ }^{1}$
}

Published online: 9 December 2019

(C) The Author(s) 2019

\begin{abstract}
Background To investigate the distribution of metastatic cancer cells in the mesentery (referred to as metastasis V) and enrich the understanding of the metastasis of colorectal cancer.

Methods A total of two hundred ninety-nine patients who received colorectal operations at the Department of Gastrointestinal Surgery, Tongji Hospital, Tongji Medical College, Huazhong University of Science and Technology between April 2018 and December 2018 were included. Samples were acquired from the dissected mesentery after the operation, and hematoxylin-eosin staining or immunohistochemistry was used to detect metastatic cancer cells. Pathological factors, including tumor position, tumor size, invasion depth, tumor differentiation, lymph node involvement, local vessel invasion, and perineural invasion, were recorded.

Results Metastatic cancer cells in the colorectal mesentery (metastasis V) were detected in 62 of 299 patients. Metastasis V was closely correlated with tumor invasion depth, lymph node metastasis, tumor differentiation, and perineural and vessel invasion by cancer cells. Metastasis $\mathrm{V}$ occurred more frequently in patients with T3 stage $(26.27 \%)$ and $\mathrm{T} 4$ stage $(40.00 \%)$ than in patients with $\mathrm{T} 1$ and $\mathrm{T} 2$ stages $(0 \%$ and $2 \%$, respectively). Metastasis $\mathrm{V}$ was frequently detected in patients with $\mathrm{N} 2 \mathrm{a}$ and $\mathrm{N} 2 \mathrm{~b}$ stage tumors $(51.72 \%$ and $61.54 \%$, respectively). Metastasis $\mathrm{V}$ was more frequently detected in patients with perineural metastasis and local vessel invasion. In addition, metastasis $\mathrm{V}$ incidences in colon and rectal cancer were similar.

Conclusion The incidence rate of metastasis $\mathrm{V}$ is correlated with tumor staging factors and occurs more frequently in advanced-stage patients.
\end{abstract}

Electronic supplementary material The online version of this article (https://doi.org/10.1007/s00268-019-05284-5) contains supplementary material, which is available to authorized users.

Jian-Ping Gong

jpgong@tjh.tjmu.edu.cn

1 Department of GI Surgery, Tongji Hospital, Tongji Medical College, Huazhong University of Science and Technology, 1095 Jiefang Ave., Wuhan 430030, Hubei, People's Republic of China

\section{Introduction}

Colorectal cancer (CRC) is a high-mortality disease worldwide [1]. A high local regional recurrence rate is one of the reasons for the high mortality rate $[2,3]$. Over time, surgeons have paid attention to reducing recurrence. RJ Heald introduced the total mesorectum excision (TME) for rectal cancer 30 years ago [4]. Recently, Hohenberger proposed complete mesocolic excision (CME) for colon cancer [5]. Their work had increased the lymph node harvest number and reduced local regional recurrence of CRC. However, lymph node dissection protocols cannot thoroughly explain the promotion of prognosis. 
A previous study reported the existence of metastatic cancer cells in adipose tissue, and metastatic cancer cells have been closely related to poor prognosis [6]. In addition, we have also discovered metastatic cancer cells and nodules in mesentery of gastric cancer [7] and colorectal cancer [8]. The metastatic cancer cells and nodules in the mesentery were not continuous with primary tumor, metastatic lymph node, or hematogenous metastasis. We assume that this metastatic pathway was different from the conventional routes (direct invasion, peritoneum dissemination, lymphatic metastasis, and hematogenous metastasis); thus, we named it "metastasis V" [7-9]. Metastasis V left behind after an operation is termed "cancer leak" and leads to poor prognosis [10]. We aimed in the current study to investigate the distribution of metastasis $\mathrm{V}$ in the colorectal mesentery and provide information for clinical treatment.

\section{Materials and methods}

\section{Patients, samples, and sectional tissue analysis}

A total of 299 patients who underwent colorectal surgery for CRC at the Department of Gastrointestinal Surgery, Tongji Hospital, Tongji Medical College, Huazhong University of Science and Technology between April 2018 and December 2018 were included in this study. All participants signed written informed consent forms for this study. This study was approved by the Ethics Committee of the first author's institute. Clinical samples of CRC were obtained from resected colorectal tissue specimens. The demographic characteristics of the 299 patients are described in Tables 1 and 2. The clinicopathological stages were determined according to the 8th edition of the AJCC Cancer Staging Manual.

\section{Metastasis V detection}

All the mesentery from the colonic wall to the ligation clip of the vessel root was obtained after the local lymph nodes were retrieved. The specimen was divided into $1 \mathrm{~cm} \times 1$ $\mathrm{cm}$ pieces and numbered (see Supplementary Figure S1) and fixed in $4 \%$ formaldehyde solution for at least $24 \mathrm{~h}$. After fixation, HE slices were generated for each piece of mesentery for the first screening. The number of slices for each specimen varied with the area of the entire obtained mesentery. If a potential or suspect metastasis $\mathrm{V}$ was found in a specimen, IHC (pan-cytokeratin, PCK) staining slices were generated and investigated for confirmation. The slices were checked by two senior pathologists.

\section{Statistical analysis}

Chi-square and ANOVA analyses were used to inspect the inter-group differences in incidence and metastasis $\mathrm{V}$ numbers, respectively. We considered a $P$ value less than 0.05 to be statistically significant. Standard statistical analyses were performed with SPSS version 22.0.

\section{Results}

\section{Patients and baseline analysis}

Two hundred ninety-nine patients were enrolled in the study. As shown in Table 1, the participants were 117 females $(39.13 \%)$ and 182 males $(60.87 \%)$. The average patient age was $56.69 \pm 11.74$ years (range 25-86). Among the patients, $289(96.66 \%)$ received radical operations, and $10(3.34 \%)$ received palliative operations because of distant metastasis or peritoneal metastasis with complications, such as obstruction and perforation. There were $48,131,110$, and 10 patients with stages I, II, III, and IV disease, respectively. The average number of retrieved lymph nodes was $16.16 \pm 9.16(2-75)$. Metastasis V was detected in 62 of the $299(20.74 \%)$ patients.

\section{Metastasis $\mathrm{V}$ occurred more frequently in patients with advanced colorectal cancer}

Tumor stage is closely related to poor prognosis in CRC [11]. We compared the incidence and average metastasis $\mathrm{V}$ numbers among patients with each stage of cancer. The Chi-square analysis showed significant differences in the incidence rates between each stage $(P<0.05)$, and the incidence of metastasis $\mathrm{V}$ in patients with advanced stage (stage III $45 / 110 ; 40.91 \%$; stage IV $7 / 10 ; 70.00 \%$ ) was higher than that in patients with stage II $(9 / 131 ; 6.87 \%)$ and stage I $(1 / 52 ; 1.92 \%)$. The ANOVA results showed that there was no significant difference in the average metastasis $\mathrm{V}$ number between those with stage I and stage II disease, and the average metastasis $\mathrm{V}$ number in stage III and stage IV patients was much higher than that in stage I and stage II patients (Fig. 1a). Therefore, metastasis V occurs more frequently in patients with advanced colorectal cancer.

\section{Metastasis $\mathrm{V}$ occurred more frequently in patients with colorectal cancer with invasion depths greater than T3}

We compared the incidence and the metastasis $\mathrm{V}$ number at different tumor invasion depths ( $\mathrm{T}$ stage) (Table 1, Fig. 1b). Most metastasis V occurred in stage T3 and T4 
Table 1 Data in 299 colorectal cancer patients

\begin{tabular}{|c|c|}
\hline Parameters & Results $^{\mathrm{a}}$ \\
\hline \multicolumn{2}{|l|}{ Gender } \\
\hline Female & $27 / 117(23.08 \%)$ \\
\hline Male & $35 / 182(19.23 \%)$ \\
\hline Age (year, mean, range) & $56.69 \pm 11.74(25-86)$ \\
\hline $\begin{array}{l}\text { Lymph nodes retrieved (mean } \pm \mathrm{SD} \text {, } \\
\text { range) }\end{array}$ & $16.16 \pm 9.12(2-75)$ \\
\hline \multicolumn{2}{|l|}{ Location of tumor } \\
\hline Colon & $24 / 138(17.39 \%)$ \\
\hline Rectum & $38 / 161(23.60 \%)$ \\
\hline \multicolumn{2}{|l|}{ Histologic grade $(G)^{\mathrm{b}}$} \\
\hline G1 & $2 / 17(11.76 \%)$ \\
\hline $\mathrm{G} 2$ & $32 / 195(15.42 \%)$ \\
\hline G3 & $28 / 87(32.18 \%)$ \\
\hline \multicolumn{2}{|l|}{ Invasive depth } \\
\hline $\mathrm{T} 1$ & $0 / 7(0.00 \%)$ \\
\hline $\mathrm{T} 2$ & $1 / 50(2.00 \%)$ \\
\hline T3 & $51 / 217(26.27 \%)$ \\
\hline $\mathrm{T} 4$ & $10 / 25(40.00 \%)$ \\
\hline \multicolumn{2}{|l|}{ Lymph node metastasis } \\
\hline NO & 9/181 (4.97\%) \\
\hline $\mathrm{N} 1$ & $24 / 68(35.29 \%)$ \\
\hline $\mathrm{N} 2 \mathrm{a}$ & $18 / 34(52.94 \%)$ \\
\hline $\mathrm{N} 2 \mathrm{~b}$ & $11 / 16(68.75 \%)$ \\
\hline \multicolumn{2}{|l|}{ Distant metastasis } \\
\hline M0 & $55 / 289(19.03 \%)$ \\
\hline M1 & $7 / 10(70.00 \%)$ \\
\hline \multicolumn{2}{|l|}{$L V I$} \\
\hline Negative & $39 / 243(16.05 \%)$ \\
\hline Positive & $23 / 46(50.00 \%)$ \\
\hline \multicolumn{2}{|l|}{ Perineural invasion } \\
\hline Negative & $28 / 225(12.44 \%)$ \\
\hline Positive & $34 / 74(45.94 \%)$ \\
\hline
\end{tabular}

LVI local vessel invasion of cancer cells

${ }^{a}$ The data were showing as (number of patients with metastasis V)/ (number of total patients in the category) (\%)

${ }^{b}$ Histologic Grade classification according to AJCC 8th, G1: well differentiated; G2: moderately differentiated; G3: poorly differentiated

patients. Chi-square analysis showed significant differences in incidence rates between different $\mathrm{T}$ stages. Metastasis $\mathrm{V}$ was more likely to occur in patients with stages T3 (51/ $217 ; 23.50 \%)$ and $\mathrm{T} 4(10 / 25 ; 40.00 \%)$ than in those with stages $\mathrm{T} 1(0 / 7 ; 0 \%)$ and $\mathrm{T} 2(1 / 50 ; 2.00 \%)$ (Table 1$)$. Moreover, ANOVA showed that the average metastasis number was also much higher in $\mathrm{T} 3$ and $\mathrm{T} 4$ patients than in $\mathrm{T} 2$ and $\mathrm{T} 1$ patients (Fig. 1b). The above results support that metastasis $\mathrm{V}$ occurs more frequently in patients with colorectal cancer with deeper invasion.
Metastasis $\mathrm{V}$ occurred more frequently in patients with local regional lymph node metastasis

Local regional lymph node metastasis ( $\mathrm{N}$ stage) can predict poor prognosis [6]. We analyzed the incidences and average metastasis $\mathrm{V}$ number in each $\mathrm{N}$ stage. Chi-square analysis showed significant differences in incidence rates between different $\mathrm{N}$ stages, and metastasis $\mathrm{V}$ appeared to occur more frequently in the $\mathrm{N}$-positive groups (N1: 35.29\%; N2a: 52.94\%; N2b: 68.75\%) than in the N-negative group $(4.97 \%)$ (Table 1). ANOVA showed that the average metastasis $\mathrm{V}$ number in the $\mathrm{N} 2 \mathrm{~b}$ group was significantly higher than that in the N2a, N1, and N0 groups combined $(P<0.05)$; the average metastasis $\mathrm{V}$ number in the N2a group was significantly higher than that in the N1 and N0 groups combined $(P<0.05)$; and the average metastasis $\mathrm{V}$ number in the $\mathrm{N} 1$ group was significantly higher than that in the N0 group $(P<0.05)$ (Fig. 1c). Therefore, metastasis $\mathrm{V}$ occurs more frequently in patients with regional lymph node metastasis.

\section{Metastasis $\mathbf{V}$ occurred more frequently in colorectal cancer with low histologic grade}

We compared the incidence and metastasis $\mathrm{V}$ number in each histologic grade. Chi-square analysis showed significant differences in incidence rates between different grades. Metastasis $\mathrm{V}$ was more likely to occur in patients with G3 $(28 / 87 ; 32.18 \%)$ than in those with G1 $(2 / 17$; $11.76 \%)$ and G2 $(32 / 195 ; 15.42 \%)$ (Table 1). Moreover, ANOVA showed that the average metastasis $\mathrm{V}$ number was also much higher in G3 patients than in G2 patients, but it was not higher in G3 patients than in G1 patients, possibly because the G1 sample size was small (Fig. 1d). The above results support that metastasis $\mathrm{V}$ occurs more frequently in colorectal cancer patients with low histologic grades.

\section{Metastasis $\mathrm{V}$ occurred more frequently in patients with local vessel invasion}

A previous study showed that metastasis $\mathrm{V}$ is the appearance of cancer cells in the mesogastrium, mesocolon, or mesorectum independent of lymph node or vessel invasion $[7,8]$. We explored whether metastasis $\mathrm{V}$ is related to local vessel invasion by cancer cells. The results showed that there was a significant difference between the groups with local vessel invasion (LVI-positive group) and without local vessel invasion (LVI-negative group), and specifically, the metastasis $\mathrm{V}$ incidence in the LVI-negative group $(39 / 243,16.05 \%)$ was significantly lower than the incidence in the LVI-positive group (23/46, 50.00\%) $(P<0.05)$; the patients without LVI had a lower metastasis $\mathrm{V}$ number than the patients with LVI $(P<0.05)$ 
Table 2 Cases in TNM classification

\begin{tabular}{llc}
\hline & TNM stage & Total $^{\mathrm{a}}$ \\
\hline I & T1N0M0 & $0 / 7(0)$ \\
I & T2N0M0 & $1 / 41(2.44 \%)$ \\
IIa & T3N0M0 & $8 / 123(6.50 \%)$ \\
IIb & T4N0M0 & $1 / 8(12.50 \%)$ \\
IIIa & T2N1M0 & $0 / 8(0)$ \\
IIIb & T3N1M0 & $15 / 46(32.61 \%)$ \\
IIIb & T3N2aM0 & $12 / 25(48.00 \%)$ \\
IIIc & T3N2bM0 & $10 / 15(66.67 \%)$ \\
IIIb & T4N1M0 & $5 / 12(41.67 \%)$ \\
IIIc & T4N2aM0 & $1 / 1(100.00 \%)$ \\
IIIc & T4N2bM0 & $2 / 3(66.67 \%)$ \\
IV & T3N0M1 & $0 / 1(0)$ \\
IV & T3N1M1 & $2 / 2(100.00 \%)$ \\
IV & T3N2M1 & $3 / 4(75.00 \%)$ \\
IV & T4N2M1 & $1 / 2(50.00 \%)$ \\
\hline
\end{tabular}

${ }^{\mathrm{a}}$ The data were showing as (number of patients with metastasis $\mathrm{V}$ )/ (number of total patients in the category) (\%)
(Fig. 1e). Thus, metastasis $\mathrm{V}$ is associated with LVI by tumor cells.

\section{Metastasis $\mathrm{V}$ occurred more frequently in patients with perineural invasion}

The results showed that there was a significant difference between the groups with perineural invasion (neuro-positive group) and without perineural invasion (neuro-negative group), and specifically, the incidence of metastasis $\mathrm{V}$ in the neuro-negative group $(28 / 225,12.44 \%)$ was significantly lower than that in the neuro-positive group (34/74, $45.94 \%)(P<0.05)$. The patients without perineural invasion had a lower metastasis $\mathrm{V}$ number than the patients with perineural invasion $(P<0.05)$ (Fig. 1f). Thus, metastasis $\mathrm{V}$ is associated with perineural invasion by tumor cells.

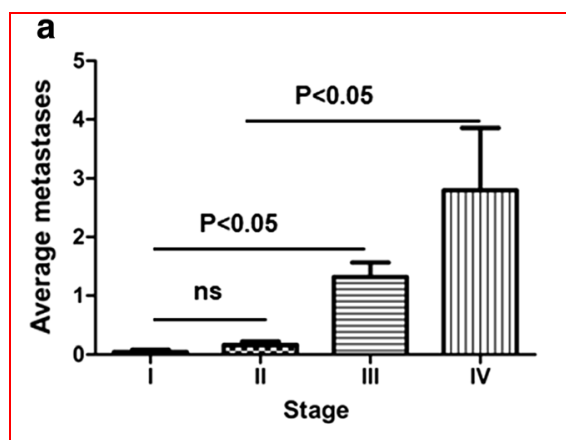

d

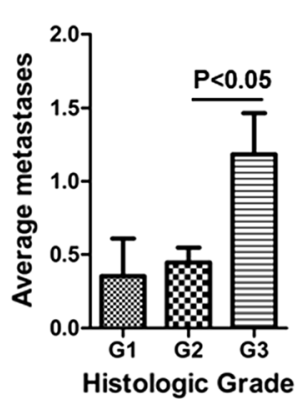

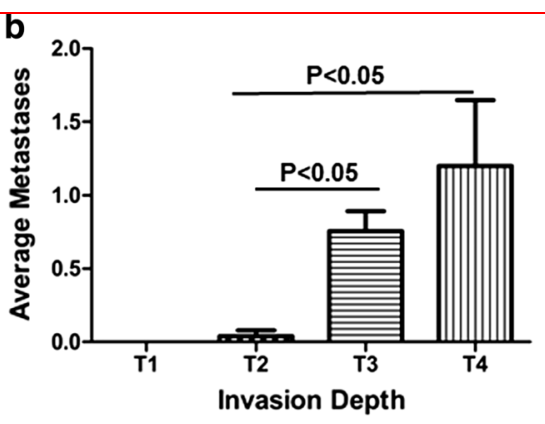

f

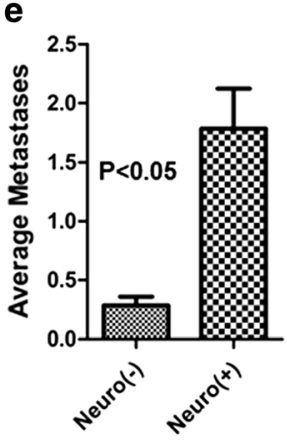

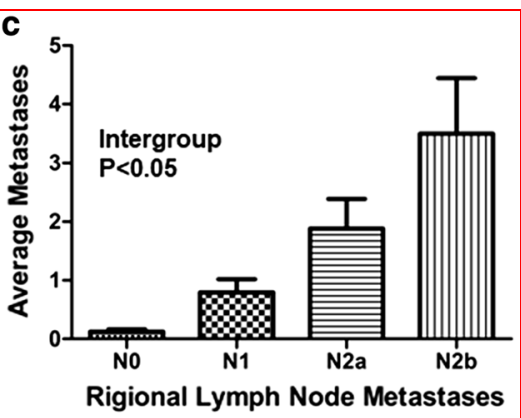

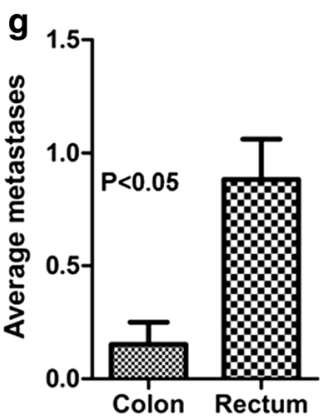

Fig. 1 Average metastases numbers in each category. a Average metastasis V number in stages I, II, III, IV, respectively. The stages were determined according to AJCC 8th. b Average metastasis V number in invasion depth T1, T2, T3, and T4, respectively. The invasion depth was determined according to AJCC 8th. c Average metastasis V number in local lymph node metastasis category N0, N1, N2a, N2b, respectively. The $\mathrm{N}$ stages were determined according to AJCC 8th. d Average metastasis $\mathrm{V}$ number in each histological differentiation category according to AJCC 8th. G1: well differentiated; G2: moderately differentiated; G3: poorly differentiated. e Average metastasis V number in subgroup without perineural metastasis [Neuro $(-)$ ) vs subgroup with perineural metastasis (Neuro $(+)$ ] 


\section{Metastasis $\mathbf{V}$ occurred more frequently in patients with rectal cancer}

The prognosis of rectal cancer is much worse than that of colon cancer [12]. Thus, we compared the metastasis V incidence among tumors in different parts of the colorectum. Metastasis V occurred more frequently in rectal cancer patients $(23.60 \%)$ than in patients with colon cancer $(17.39 \%)$ (Table 1). The Chi-square analysis was not significant $(P>0.05)$. However, ANOVA showed that there was a significant difference between the average metastasis $\mathrm{V}$ numbers in rectal cancer patients and colonic cancer patients, and the average metastasis $\mathrm{V}$ number in rectal cancer patients was significantly higher than that in colon cancer patients (Fig. 1g). Therefore, the incidence of metastasis $\mathrm{V}$ was similar between colonic cancer and rectal cancer patients, but the metastasis $\mathrm{V}$ number was higher in rectal cancer patients than in colon cancer patients.

We concluded that metastasis $\mathrm{V}$ occurs more frequently in advanced stage patients (stage III and stage IV) and patients with deeper tumor invasion, local lymph node metastasis, low histologic grade, LVI, and perineural metastasis. We also analyzed the relationship between metastasis $\mathrm{V}$ and clinical factors involved above in colon cancer and rectal cancer separately. The results in colon cancer and rectal cancer showed similar trend except for the differentiation category (Figures S2, S3; Tables S1, S2). There was no significant difference between the metastasis $\mathrm{V}$ incidence rates in colon cancer and rectal cancer patients.

\section{Discussion}

Local recurrence is an important factor that affects CRC prognosis [13]. Lymph node dissection has been proven to be effective at improving the prognosis of colorectal cancer [14-16]. Further, metastatic cancer cells have been identified in the mesentery, and patients with metastatic cancer cells in adipose tissue around tumors have a relatively worse prognosis [17]. However, the distribution of metastatic cancer cells has rarely been studied.

Metastatic cancer cells in the adipose tissue were first called tumor deposits (TD) by Gabriel et al. [16] and were considered the result of vascular tumor dissemination. TD was further studied and defined as adenocarcinoma within adipose or fibrous tissue around that was not associated with a lymph node [17-19]. Later, isolated tumor cells (ITC) was also proposed and focused on single tumor cell or cell clusters in lymph node, hematologic system, bone marrow, etc., and has also proven associated to poor prognosis [20, 21].
In our previous studies, we discovered metastatic cancer cells in the mesentery of the stomach, colon, and rectum and proposed the definition of metastasis V [7-9]. Metastasis $\mathrm{V}$ defined a novel metastasis route of gastric cancer and colorectal cancer that occurred in the mesentery of stomach and colorectum. An important character of metastasis $\mathrm{V}$ is removable by complete mesentery excision operations and can "leak out" from ruptured mesentery. Complete mesentery excision in gastric cancer has been proven less "cancer leak" and with favorable prognosis [10]. We are also expanding the study on colorectal cancer. Thus, the distribution of metastasis $\mathrm{V}$ is meaningful for clinical strategy selection.

In this study, we have shown that metastasis $\mathrm{V}$ incidence is related to tumor stage. Metastasis $\mathrm{V}$ occurs more frequently in $\mathrm{N}$-positive patients, and those with cancer in the N2b stage have a much higher metastasis V incidence than those with stage N2a, who in turn have a much higher incidence than those with $\mathrm{N} 1$. Consistent with our previous study, metastasis $\mathrm{V}$ occurs more in $\mathrm{T} 3$ or $\mathrm{T} 4$ stage disease than in $\mathrm{T} 1$ or $\mathrm{T} 2$ disease. Interestingly, we also noticed that metastasis $\mathrm{V}$ occurs more frequently in patients with local perineural or vessel invasion.

The limitation of this study is the lack of long-term survival data; we will continue to follow these patients and report the follow-up results, and an additional randomized clinical trial will be conducted to study the efficiency and reliability of CME/TME in preventing "cancer leak" and reduce tumor recurrence.

Authors' contribution JG conceived of and designed the study; CM contributed to data acquisition, analysis and interpretation and wrote the article; YT revised and reviewed the article; all authors have reviewed and approved the final manuscript.

Funding This work was supported by grants from the National Science Foundation of China, Grant number: 81874185.

\section{Compliance with ethical standards}

Conflict of interest The authors declare that they have no conflicts of interest.

Ethical standards All procedures performed in the study were done so in accordance with the ethical standards of Tongji Hospital Ethics Committee, Wuhan, China.

Open Access This article is distributed under the terms of the Creative Commons Attribution 4.0 International License (http://crea tivecommons.org/licenses/by/4.0/), which permits unrestricted use, distribution, and reproduction in any medium, provided you give appropriate credit to the original author(s) and the source, provide a link to the Creative Commons license, and indicate if changes were made. 


\section{References}

1. Ferlay J et al (2015) Cancer incidence and mortality worldwide: sources, methods and major patterns in GLOBOCAN 2012. Int J Cancer 136(5):E359-E386

2. Fleshman J, Branda ME, Sargent DJ et al (2019) Disease-free survival and local recurrence for laparoscopic resection compared with open resection of stage II to III rectal cancer: follow-up results of the ACOSOG Z6051 randomized controlled trial. Ann Surg 269(4): 589-595. https://doi.org/10.1097/SLA.0000000000003002

3. Bouvier AM et al (2015) Incidence and patterns of late recurrences in colon cancer patients. Int J Cancer 137(9):2133-2138

4. Heald RJ, Husband EM, Ryall RDH (2010) The mesorectum in rectal cancer surgery - the clue to pelvic recurrence? Br J Surg 69(10):613-616

5. Hohenberger W et al (2009) Standardized surgery for colonic cancer: complete mesocolic excision and central ligation-technical notes and outcome. Colorectal Dis 11(4):354-364

6. Nakamura K et al (2005) Evaluation of prognostic significance in extracapsular spread of lymph node metastasis in patients with gastric cancer. Surgery 137(5):511-517

7. Xie D et al (2013) Mesogastrium: a fifth route of metastasis in gastric cancer? Med Hypotheses 80(4):498-500

8. Luo X-L et al (2017) Detection of metastatic cancer cells in mesentery of colorectal cancer patients. World J Gastroenterol 23(34):6315

9. Daxing X et al (2015) Detection and characterization of metastatic cancer cells in the mesogastrium of gastric cancer patients. PLoS ONE 10(11):e0142970

10. Xie D, Wang Y, Shen J et al (2018) Detection of carcinoembryonic antigen in peritoneal fluid of patients undergoing laparoscopic distal gastrectomy with complete mesogastric excision. Br J Surg 105(11):1471-1479

11. Chang GJ et al (2007) Lymph node evaluation and survival after curative resection of colon cancer: systematic review. J Natl Cancer Inst 99(6):433-441
12. Astler VB, Coller FA (1954) The prognostic significance of direct extension of carcinoma of the colon and rectum. Ann Surg 139(6):846

13. Abulafi AM, Williams NS (1994) Local recurrence of colorectal cancer: the problem, mechanisms, management and adjuvant therapy. Br J Surg 81(1):7-19

14. Le Voyer TE, Sigurdson ER, Hanlon AL et al (2003) Colon cancer survival is associated with increasing number of lymph nodes analyzed: a secondary survey of intergroup trial INT-0089. J Clin Oncol 21(15):2912-2919

15. Moriya Y, Sugihara K, Akasu T et al (1997) Importance of extended lymphadenectomy with lateral node dissection for advanced lower rectal cancer. World J Surg 21(7):728-732. https://doi.org/10.1007/s002689900298

16. Gabriel W, Dukes C, Bussey H (1935) Lymphatic spread in cancer of the rectum. Br J Surg 23(90):395-413

17. Veronese N, Nottegar A, Pea A et al (2015) Prognostic impact and implications of extracapsular lymph node involvement in colorectal cancer: a systematic review with meta-analysis. Ann Oncol 27(1):42-48

18. Goldstein NS, Turner JR (2000) Pericolonic tumor deposits in patients with $\mathrm{T} 3 \mathrm{~N}+\mathrm{M} 0$ colon adenocarcinomas: markers of reduced disease free survival and intra-abdominal metastases and their implications for TNM classification. Cancer 88(10):2228-2238

19. Harrison JC et al (1995) Impact of the Crohn's-like lymphoid reaction on staging of right-sided colon cancer: results of multivariate analysis. Hum Pathol 26(1):31-38

20. Luchini $\mathrm{C}$ et al (2016) Extranodal extension is an important prognostic parameter for both colonic and rectal cancer. Ann Oncol 27(5):955-956

21. Hermanek P, Hutter RV, Sobin LH, Wittekind C (1999) Classification of isolated tumor cells and micrometastasis. Cancer Interdiscip Int J Am Cancer Soc 86(12):2668-2673

Publisher's Note Springer Nature remains neutral with regard to jurisdictional claims in published maps and institutional affiliations. 